\title{
Internal friction phenomena in composites based on PZT-type ferroelectric powder and ferrites ${ }^{\star}$
}

\author{
Radosław Zachariasz ${ }^{\mathrm{a}}$, Dariusz Bochenek, and Joanna Bartkowska \\ University of Silesia, Institute of Technology and Mechatronics, 12, Żytnia St., 41-200 Sosnowiec, Poland
}

Received 21 June 2015 / Received in final form 17 September 2015

Published online 1 February 2016

(C) The Author(s) 2016. This article is published with open access at Springerlink.com

\begin{abstract}
The aim of the work was to determine the phenomena of internal friction (mechanical losses) occurring in ferroelectric-ferromagnetic composites created based on PZT-type ferroelectric powder and ferrite. The composites were obtained using ceramic powders - multi-component PZT-type solid solutions with ferroelectric properties. Their magnetic component included zinc-nickel powder $\mathrm{Ni}_{0.64} \mathrm{Zn}_{0.36} \mathrm{Fe}_{2} \mathrm{O}_{4}$. $30 \times 10 \times 1 \mathrm{~mm}^{3}$ test specimens were obtained using free sintering. Temperature $Q^{-1}(T)$ and amplitude $Q^{-1}(\varepsilon)$ internal friction dependencies were determined. Wide high temperature maxima were observed with regard to the internal friction temperature dependencies obtained for the tested specimens. The conducted measurements of amplitude (isothermal) dependencies of internal friction $Q^{-1}(\varepsilon)$ for the tested composites have allowed for interpreting the previously observed maximum on the temperature dependencies of internal friction.
\end{abstract}

\section{Introduction}

In order to broaden the application possibilities of composite materials obtained based on PZT-type ferroelectric powder and ferrites, it is necessary to learn their physical, chemical and mechanical properties, as well as their actual structure $[1,2]$. Knowledge regarding the relation between the chemical composition, crystalline structure and electro-physical properties allows for obtaining this type of materials with increasingly better and more stable properties, necessary for functional application in modern technology. In testing multiferroic materials, including composite ones, quick development of modern testing methods is observed, mainly with respect to non-destructive methods. More frequent use of mechanical spectroscopy, and especially of the internal friction method, is observed. Vast interest in the method based on measuring internal friction when testing the actual structure of composite materials is brought about by the fact that, while observing macroscopic vibrations of a specimen, one may obtain information regarding the behavior of the tested material on the atomic level. Due to its high sensitivity to changes in the concentration of point defects, interaction between defects and changes in the actual structure, the method is applied in the following processes: testing the kinetics of phase transformations, mechanical properties, dynamics of the dislocation movement, secondary phase precipitation processes, organizing

\footnotetext{
* Contribution to the Topical Issue "Materials for Dielectric Applications", edited by Maciej Jaroszewski and Sabu Thomas.

a e-mail: radoslaw.zachariasz@us.edu.pl
}

processes, as well as structure changes occurring during the aging process $[3-5]$.

The aim of the work was to obtain ferroelectricmagnetic composites based on PZT-type ferroelectric powders and nickel-zinc ferrite, and then to measure their mechanical properties.

The internal friction method was applied in the obtained composite specimens. Internal friction is caused by irreversible energy losses occurring in solids as a result of numerous processes involving, among others, crystal lattice defects. It is characterized by inelastic behavior of solids under the impact of external stresses and manifests itself as partial loss of mechanical vibration energy (a portion of the mechanical energy is transformed into thermal energy) [6-9]. The determination of mechanical losses $Q^{-1}$ may be performed both through temperature measurements (at constant measuring frequency) and frequency measurements (at constant temperature) [10-12].

\section{Production technology and performed tests}

The test material included ferroelectric-ferromagnetic composites was obtained by combining PZT-type ferroelectric powder with ferromagnetic zinc-nickel ferrite powder $\left(\mathrm{Ni}_{0.64} \mathrm{Zn}_{0.36} \mathrm{Fe}_{2} \mathrm{O}_{4}\right)$. The ferroelectric powder consisted of two PZT-type compositions: $\mathrm{Pb}_{0.84} \mathrm{Ba}_{0.16}\left(\mathrm{Zr}_{0.54} \mathrm{Ti}_{0.46}\right) \mathrm{O}_{3}+1.0 \%$ at. $\mathrm{Nb}_{2} \mathrm{O}_{5}(\mathrm{PBZTN})$ and $\mathrm{Pb}\left(\mathrm{Zr}_{0.51} \mathrm{Ti}_{0.49}\right) \mathrm{O}_{3}+0.2 \%$ at. $\mathrm{Bi}_{2} \mathrm{O}_{3}+0.03 \%$ at. $\mathrm{Nb}_{2} \mathrm{O}_{5}+0.06 \%$ at. $\mathrm{MnO}_{2}$ (PZTBNM). The initial components for obtaining PZT-type powders included oxides: $\mathrm{PbO}, \mathrm{ZrO}_{2}, \mathrm{TiO}_{2}, \mathrm{Nb}_{2} \mathrm{O}_{5}, \mathrm{Bi}_{2} \mathrm{O}_{3}, \mathrm{MnO}_{2}$ and barium carbonate $\mathrm{BaCO}_{3}$. The main component of 


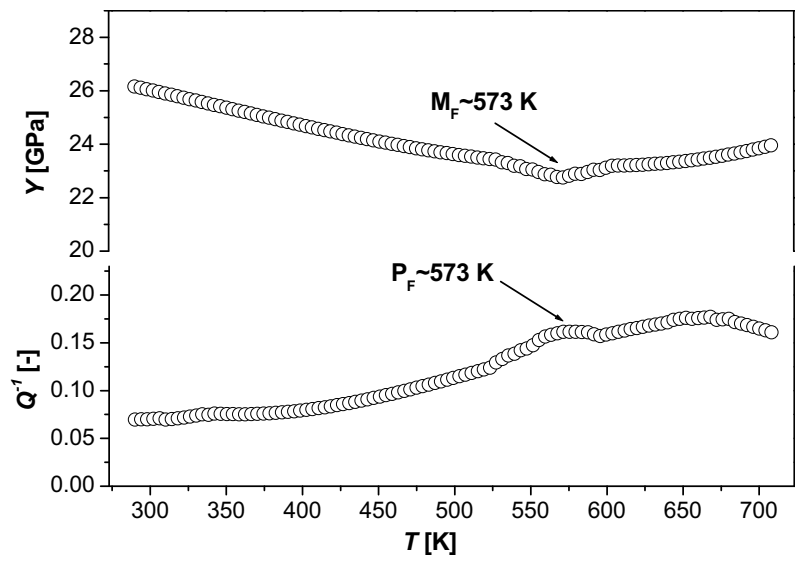

Fig. 1. Temperature dependencies of internal friction $Q^{-1}(T)$ and Young modulus $Y(T)$ for the PBZTN-ferrite composite within a temperature range from $293 \mathrm{~K}$ to $723 \mathrm{~K}$.

the composite - PZT-type ferroelectric powder - was synthesized by way of sintering a mixture of simple oxides in the solid phase (compacting method) in conditions of $T_{\text {synth }}=1123 \mathrm{~K}, t_{\text {synth }}=2 \mathrm{~h}$. The second composite component with ferromagnetic properties $\left(\mathrm{Ni}_{0.64} \mathrm{Zn}_{0.36} \mathrm{Fe}_{2} \mathrm{O}_{4}\right.$ ferrite powder $)$ was synthesized by way of calcination in conditions of $1273 \mathrm{~K} / 4$ h. $90 \%$ of the PZT-NiZnFe composite type was made up by ceramic powder, while ferrite powder constituted $10 \%$ of the composition. Powders of the initial components were wet-mixed (in ethyl alcohol) in a FRITSCH Pulwerisette 6-type planetary ball mill for $8 \mathrm{~h}$. Synthesizing of composite powders was performed by way of calcination in conditions of $T_{\text {synth }}=1223 \mathrm{~K}$ and $t_{\text {synth }}=2 \mathrm{~h}$, while their compacting (sintering) was done by means of free sintering of compacts in conditions of $T_{s}=1523 \mathrm{~K}$ and $t_{s}=2 \mathrm{~h}$. Multiferroic composite specimens were marked as PBZTN-ferrite and PZTBNM-ferrite. After sintering, $30 \times 10 \times 1 \mathrm{~mm}^{3}$ cuboid specimens were ground and polished, after which silver paste electrodes were applied on their surface.

Measurements of temperature and amplitude dependencies of internal friction $Q^{-1}$ and resonance frequency $f_{r}$ were performed on a RAK-3 automatic acoustic frequency relaxator. Values of Young modulus $Y$ were determined from the following relation:

$$
Y=94.68\left(\frac{l_{r}}{h}\right)^{3} \frac{m_{d}}{b} f_{r}^{2}
$$

where: $l_{r}$ - length, $h$ - thickness, $b$ - width, $m$ - mass of vibratile part of specimen.

Temperature dependencies $Q^{-1}(T)$ were determined at a heating rate of $3 \mathrm{deg} / \mathrm{min}$, while amplitude dependencies $Q^{-1}(\varepsilon)$ - at suitable constant temperatures.

\section{Test results and discussion}

Temperature dependencies $Q^{-1}(T)$ and $Y(T)$ for the tested composites, carried out within a temperature range from $293 \mathrm{~K}$ to $723 \mathrm{~K}$, are presented in Figures 1 and 2.

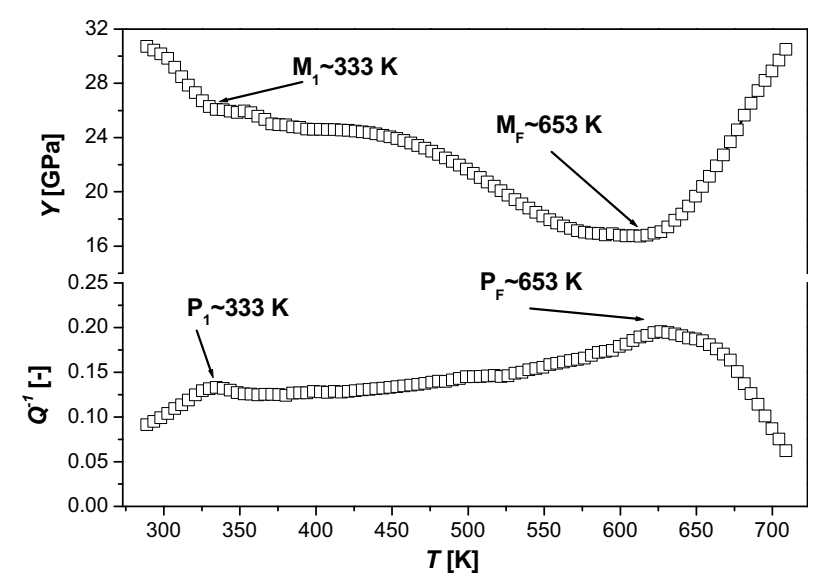

Fig. 2. Temperature dependencies of internal friction $Q^{-1}(T)$ and Young modulus $Y(T)$ for the PZTBNM-ferrite composite within a temperature range from $293 \mathrm{~K}$ to $723 \mathrm{~K}$.

In the case of the PBZTN-ferrite composite (Fig. 1), together with an increase of temperature there occurs a clear increase of the value of mechanical losses with a dispersed $P_{F}$ maximum at a temperature of approx. $573 \mathrm{~K}$. At the same time, characteristic $M_{F}$ minimum correlating with the $P_{F}$ maximum is observed on the temperature dependence of Young modulus $Y(T)$. Such behavior of both the $Q^{-1}(T)$ as well as $Y(T)$ dependence indicates the occurrence of a phase change in this temperature area. This is illustrated by the increase of mechanical losses $Q^{-1}$ with a simultaneous decrease of the value of Young modulus $Y$. This change is related to the phase transition of the electric sub-system while transforming from a ferroelectric state to a para-electric one.

Similar behavior of temperature dependencies $Q^{-1}(T)$ and $Y(T)$ is observed for the second tested composite, i.e. PZTBNM-ferrite. Together with the increase of temperature, an increase of the value of mechanical losses and a decrease of the value of the Young modulus occur. Moreover, at a temperature of approx. $333 \mathrm{~K}$ maximum internal friction $P_{1}$ and its correlating minimum $M_{1}$ are observed. These anomalies are related to the occurrence of two phases in the composition of the composite, i.e. a tetragonal and rhombohedral phase originating from the morphotropic area of the PZT-type ferroelectric component. At a temperature of approx. $653 \mathrm{~K}$, there is a characteristic $P_{F}$ maximum on the $Q^{-1}(T)$ curve, correlating with an $M_{F}$ minimum on the $Y(T)$ curve, related to the ferroelectric-paraelectric phase transition. Beyond this temperature, rapid increase is observed of the value of Young modulus $Y$, related to the change of the crystalline structure to a regular system.

For the purpose of confirming the mechanisms responsible for changes in internal friction values, measurements were carried out of internal friction in the function of deformation amplitude $Q^{-1}(\varepsilon)$. $\varepsilon$ values were determined based on the following dependence [13]:

$$
\varepsilon_{m}=\frac{4 d}{\pi m l^{2}} \frac{\alpha_{n}^{2}}{f_{n}^{2}} \frac{C_{e} V_{e} v_{1}}{g \delta} \times 10^{-5}
$$




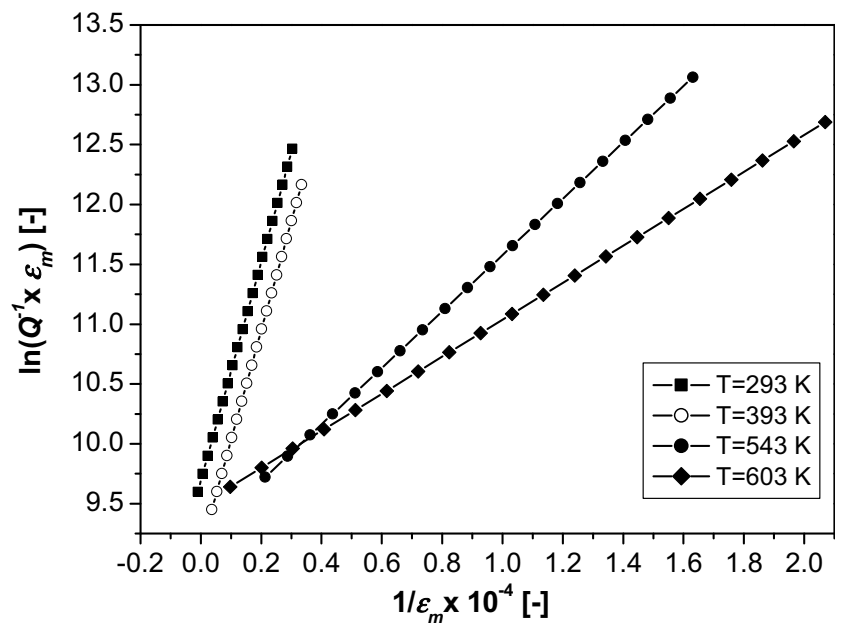

Fig. 3. Amplitude dependencies of internal friction $\ln \left(Q^{-1} \times\right.$ $\left.\varepsilon_{m}\right)=f\left(1 / \varepsilon_{m}\right)$ for the PBZTN-ferrite composite.

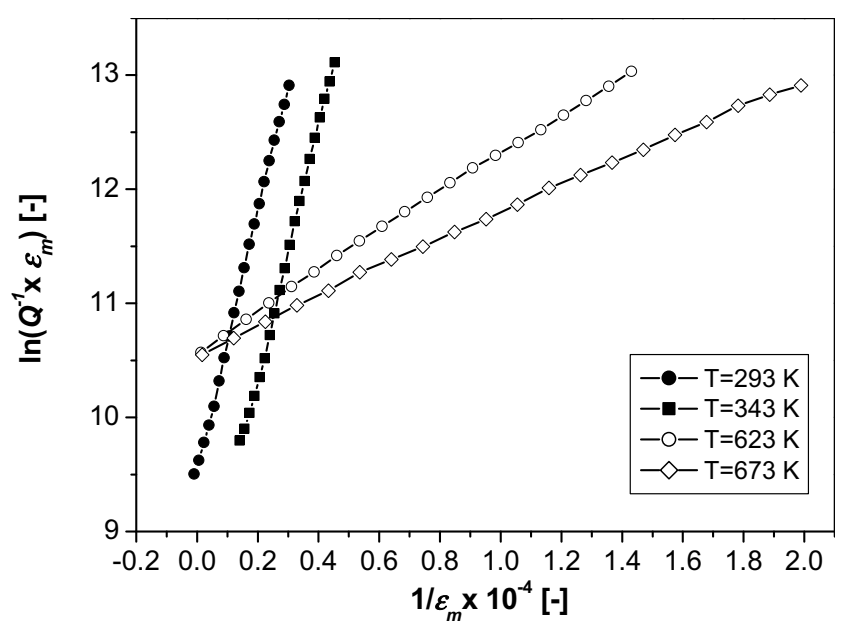

Fig. 4. Amplitude dependencies of internal friction $\ln \left(Q^{-1} \times\right.$ $\left.\varepsilon_{m}\right)=f\left(1 / \varepsilon_{m}\right)$ for the PZTBNM-ferrite composite.

where: $d$ - specimen thickness $[\mathrm{cm}] ; \alpha_{n}^{2}-$ a constant which characterizes the basic tone of resonance frequency (0.879); $C_{e}$ - capacitance created between the electrode and the $[\mathrm{pF}]$ specimen surface; $V_{p}$ - voltage on electrodes $[\mathrm{V}], l^{2}$ - area of the vibrating part of the specimen $\left[\mathrm{cm}^{2}\right], v_{1}-$ amplitude of the voltage applied from an alternating voltage generator $[\mathrm{V}], m-$ mass of the vibrating part of the specimen $[\mathrm{g}], f_{n}$ - vibration frequency of the specimen $[\mathrm{Hz}], g$-distance between the specimen and the electrode $[\mathrm{cm}], \delta$ - logarithmic damping decrement.

Figures 3 and 4 present amplitude dependencies of internal friction $\ln \left(Q^{-1} \times \varepsilon_{m}\right)=f\left(1 / \varepsilon_{m}\right)$ for the tested composites. The amplitude dependence of internal friction is described by the following expression:

$$
Q^{-1}=\frac{C_{1}}{\varepsilon} \exp \left(-\frac{C_{2}}{\varepsilon}\right)
$$

where: $C_{2}=(K \times a \times \delta) / L_{C},(K, a, \delta$ - material constants $)$.

Analysis of IF amplitude dependencies obtained for the tested ceramics was conducted in accordance with
Table 1. Values of coefficient $C_{2}$ and $L_{C}$ for the tested composites.

\begin{tabular}{ccc}
\hline & PBZTN-ferrite PZTBNM-ferrite \\
\hline$C_{2}$ coefficient at $T=293 \mathrm{~K}$ & 9.88 & 9.86 \\
$L_{C}$ at $T=293 \mathrm{~K}$ & 1.00 & 1.00 \\
$C_{2}$ coefficient at $T=343 \mathrm{~K}$ & - & 9.37 \\
$L_{C}$ at $T=343 \mathrm{~K}$ & - & 1.05 \\
$C_{2}$ coefficient at $T=393 \mathrm{~K}$ & 9.54 & - \\
$L_{C}$ at $T=393 \mathrm{~K}$ & 1.04 & - \\
$C_{2}$ coefficient at $T=543 \mathrm{~K}$ & 3.14 & - \\
$L_{C}$ at $T=543 \mathrm{~K}$ & 3.15 & - \\
$C_{2}$ coefficient at $T=603 \mathrm{~K}$ & 2.13 & - \\
$L_{C}$ at $T=603 \mathrm{~K}$ & 4.64 & - \\
$C_{2}$ coefficient at $T=623 \mathrm{~K}$ & - & 2.95 \\
$L_{C}$ at $T=623 \mathrm{~K}$ & - & 3.34 \\
$C_{2}$ coefficient at $T=673 \mathrm{~K}$ & - & 1.96 \\
$L_{C}$ at $T=673 \mathrm{~K}$ & - & 5.03 \\
\hline
\end{tabular}

the internal friction model developed by Granato and Lücke [14]. This model assumes that dislocations are anchored by point defects. Thus, there is a certain characteristic parameter of the length of dislocation lines marked as $L_{C}$, which is inversely proportional to coefficient $C_{2}$ [14]. The $L_{C}$ parameter can be desribed as the length of a dislocation line between the points of weak anchoring on doping atoms. Figures 3 and 4 clearly show that the obtained rectilinear dependencies have a different inclination angle. This proves that the domain wall may be treated as a set of dislocation lines. After performing analysis of each rectilinear dependency, the value of coefficient $C_{2}$ and then the parameter of the length of dislocation lines $L_{C}$ may be determined (Tab. 1). The increase of the $L_{C}$ value at subsequent higher temperatures, especially at $673 \mathrm{~K}$ in the paraelectric phase, indicates an increase in size of the domain walls. This confirms the changes occurring as a result of phase transition in the tested composites.

\section{Conclusions}

In the work, results were presented of testing mechanical properties for two ferroelectric-magnetic composites. Low values of internal friction (mechanical losses) within the entire temperature range were observed in both composites. Phase transition from the ferroelectric to the paraelectric state in the case of PBZTN-ferrite composite with a Ba admixture occurred at approx. $573 \mathrm{~K}$, while for the PZTBNM-ferrite composite with a hard Mn admixture, among others, temperature shift of the phase transition was observed towards higher temperatures up to approx. $653 \mathrm{~K}$. Low values of mechanical losses and high temperature values in the phase transition indicate good mechanical properties of the tested composites as well as the possibility of their application for work in a broad range of temperatures. The tested composites show equally high values of the dynamic Young modulus. 


\section{References}

1. D. Bochenek, P. Niemiec, R. Zachariasz, A. Chrobak, G. Ziółkowski, Arch. Metall. Mater. 58, 1013 (2013)

2. E. Nogas-Ćwikiel, Metall. Mater. 56, 1065 (2011)

3. R. Zachariasz, J. Ilczuk, D. Bochenek, Solid State Phenomena 89, 303 (2003)

4. B. Zhang, F.Q. Zu, K. Zhen, J.P. Shui, P. Wen, J. Phys.: Condens. Matter 14, 7461 (2002)

5. F. Yan, X. Chen, P. Bao, Y. Wang, J. Liu, J. Appl. Phys. 87, 1453 (2000)

6. A. Puskar, Internal Friction of Materials (Cambridge International Science Publishing, Cambridge, 2001)

7. S. Elkoun, L. David, L.B. Magalas, Solid State Phenomena 89, $31(2003)$

8. C. Wang, Q.F. Fang, Y. Shi, Z.G. Zhu, Mater. Res. Bull. 36, 2657 (2001)

9. R. Zachariasz, A. Zarycka, J. Ilczuk, Material Science Poland 25, 781 (2007)
10. M.L. Gutierrez-Urrutia, E. Carreno-Morelli, B. Guisolan, R. Schaller, J. San-Juan, Mater. Sci. Eng. A 370, 435 (2004)

11. D. Bochenek, R. Zachariasz, Arch. Metall. Mater. 54, 903 (2009)

12. R. Zachariasz, D. Bochenek, Arch. Metall. Mater. 54, 895 (2009)

13. B.S. Berry, W.C. Pritchet, IBM J. Res. Development 334, 334 (1975)

14. A. Granato, K. Lücke, Phys. Acoustics 4, 225 (1966)

Open Access This is an open access article distributed under the terms of the Creative Commons Attribution License (http://creativecommons.org/licenses/by/4.0), which permits unrestricted use, distribution, and reproduction in any medium, provided the original work is properly cited. 